\title{
In utero vitamin D deficiency predisposes offspring to long-term adverse adipose tissue effects
}

\author{
Anthony M Belenchia', Sarah A Johnson ${ }^{2,3}$, Mark R Ellersieck4, Cheryl S Rosenfeld2,3 \\ and Catherine A Peterson ${ }^{1}$
}

1Department of Nutrition and Exercise Physiology, University of Missouri, Columbia, Missouri, USA 2Department of Biomedical Sciences, University of Missouri, Columbia, Missouri, USA

${ }^{3}$ Bond Life Sciences Center, University of Missouri, Columbia, Missouri, USA

${ }^{4}$ Department of Statistics, University of Missouri, Columbia, Missouri, USA

\begin{abstract}
The fetal period represents an important window of susceptibility for later obesity and metabolic disease. Maternal vitamin D deficiency (VDD) during pregnancy is a global concern that may have long-lasting consequences on offspring metabolic health. We sought to determine whether a VDD in utero environment affects fetal adipose tissue development and offspring metabolic disease predisposition in adulthood. Furthermore, we sought to explore the extent to which the VDD intrauterine environment interacts with genetic background or postnatal environment to influence metabolic health. Eight-week-old $\mathrm{P}_{0}$ female C57BL/6J mice were fed either a VDD diet or sufficient diet (VDS) from four weeks before pregnancy (periconception) then bred to male $A^{\text {vy/a mice. }}$ Females were maintained on the diets throughout gestation. At weaning, $A^{v / / a}$ and a/a male $F_{1}$ offspring were randomized to low-fat (LFD) or high-fat diet (HFD) until 19 weeks of age, at which point serum and adipose tissue were harvested for analyses. Mice born to VDD dams weighed less at weaning than offspring born to VDS dams but experienced rapid weight gain in the four weeks post weaning, and acquired a greater ratio of perigonadal (PGAT) to subcutaneous (SQAT) than control offspring. Additionally, these mice were more susceptible to HFD-induced adipocyte hypertrophy. Offspring of VDD dams also had greater expression of Pparg transcript. These novel findings demonstrate that in utero VDD, an easily correctable but highly prevalent health concern, predisposes offspring to long-term adipose tissue consequences and possible adverse metabolic health complications.
\end{abstract}

Correspondence should be addressed to C A Peterson Email petersonca@missouri.edu

\section{Introduction}

Vitamin D deficiency (VDD) is a global health concern for pregnant women, with prevalence rates as high as $84 \%$ in some populations (Sachan et al. 2005). Given the strong association between maternal serum and placental/cord blood 25-hydroxyvitamin D (25[OH]D) concentrations, maternal vitamin D status is considered
(C) 2017 Society for Endocrinology Printed in Great Britain an excellent indicator of internal fetal vitamin D status (Novakovic et al. 2012). Reports on human pregnancies demonstrate an association between maternal VDD and fetal growth restriction (Miliku et al. 2016); however, this effect appears to be highly dependent on the severity of hypovitaminosis $\mathrm{D}$ and when during pregnancy 
the deficiency is experienced (Leffelaar et al. 2010, Burris et al. 2012, Schneuer et al. 2014, Eckhardt et al. 2015). Maternal VDD has also been independently linked to several negative metabolic health outcomes in humans, including excess adiposity and related insulin resistance (IR) in later life (Krishnaveni et al. 2011, Crozier et al. 2012). Further support for a causal relationship between maternal VDD and both impaired fetal development and adverse metabolic health outcomes has recently been documented in rodent models subjected to in utero VDD (Reichetzeder et al. 2014, Maia-Ceciliano et al. 2016). Yet, data are lacking on the specific effects of maternal VDD on offspring propensity for excess adiposity and/or associated metabolic complications.

Aims of this study presented herein were threefold: (1) to determine the consequences of maternal VDD on offspring whole body growth and adipose tissue-specific growth/development; (2) to explore the potential for the intrauterine VDD environment to interact with the postnatal environment and/or genetic background to influence metabolic health; and (3) to explore the molecular mechanisms by which maternal VDD might influence adipose tissue in offspring.

\section{Materials and methods}

\section{Animals}

All experiments were approved by the University of Missouri (MU) Animal Care and Use Committee. Eightweek-old female C57BL/6J (a/a) mice were obtained from Jackson Laboratory and maintained (2littermates/ cage) at $24^{\circ} \mathrm{C}$ at the MU Animal Sciences Research Center on a 12-h light/darkness cycle (07:00-19:00 h). To minimize any other extrinsic confounders, animals were maintained under uniform animal husbandry conditions including same room, same water bottles and source, bedding, randomized shelf position and same personnel handling all animals; thus the only extrinsic variable was diet. To produce a maternal VDD model and VDS controls, female C57BL/6J mice were randomized to a refined VDD (Research Diets D1007301; New Brunswick, NJ, USA) or a refined VDS (AIN-93G; Research Diets D10012G) diet for a four-week deficiency induction period (Table 1). Vitamin D status of both groups was confirmed by measuring serum concentrations of $25(\mathrm{OH})$ D weekly for the first four weeks after randomization. By the study period termination, VDD-fed animals
Table 1 Maternal and offspring diet compositions.

\begin{tabular}{|c|c|c|c|c|c|c|}
\hline \multirow[b]{2}{*}{ Ingredient } & \multicolumn{2}{|c|}{ VDS/LFD } & \multicolumn{2}{|r|}{ VDD } & \multicolumn{2}{|r|}{ HFD } \\
\hline & $\mathrm{g} \%$ & kcal\% & $\mathrm{g} \%$ & kcal\% & $g \%$ & kcal\% \\
\hline Protein & 20.0 & 20 & 20 & 20 & 20 & 20 \\
\hline Carbohydrate & 64.0 & 64 & 64 & 64 & 41 & 35 \\
\hline Fat & 7.0 & 16 & 7 & 16 & 24 & 45 \\
\hline \multirow[t]{2}{*}{$\mathrm{kcal} / \mathrm{g}$} & 4.0 & & 4.0 & & 4.8 & \\
\hline & IU & Amount & IU & Amount & IU & Amount \\
\hline Vitamin $D_{3}$ & 10 & $1 \mathrm{IU} / \mathrm{g}$ & - & $0 \mathrm{IU} / \mathrm{g}$ & 10 & $1 \mathrm{IU} / \mathrm{g}$ \\
\hline Calcium & & $5 \mathrm{mg} / \mathrm{g}$ & & $5 \mathrm{mg} / \mathrm{g}$ & & $5 \mathrm{mg} / \mathrm{g}$ \\
\hline Phosphorous & & $3 \mathrm{mg} / \mathrm{g}$ & & $3 \mathrm{mg} / \mathrm{g}$ & & $3 \mathrm{mg} / \mathrm{g}$ \\
\hline
\end{tabular}

HFD, high-fat diet; LFD, low-fat diet; VDD, vitamin D deficient; VDS, vitamin D sufficient.

achieved VDD $(19.5 \pm 7.7 \mathrm{nmol} / \mathrm{L})$ and the animals on the VDS diet maintained sufficient vitamin D status $(81.8 \pm 14.4 \mathrm{nmol} / \mathrm{L})$. While the levels of VDD in rodents are not clearly established, the observed concentrations are consistent with what is considered sufficient/ deficient in humans (Ross et al. 2011). Additionally, our vitamin D-deficient dams achieved serum 25(OH)D concentrations that were similar to other studies using rodent models to examine the effects of maternal VDD on offspring outcomes (Giulietti et al. 2004, O'Loan et al. 2007, Burne et al. 2011).

Animals were provided free access to diets and water. After a 4-week VDD inducement period, females from both groups were paired with male viable yellow agouti $\left(A^{v y / a}\right)$ mice for breeding. This breeding scheme provides $a / a$ and $A v y / a \mathrm{~F}_{1}$ progeny exhibiting a range of coat colors, from which only yellow coat color $A^{v y} / a$ male mice were used in the current studies. All dams were continued on their assigned diets until parturition, at which point, $\mathrm{P}_{0}$ females were maintained on VDS diet through lactation. This timeline approach is similar to previously described reports that have shown maternal VDD can lead to offspring neurobehavioral disruptions (Almeras et al. 2007, Harms et al. 2008, Fernandes de Abreu et al. 2010, Burne et al. 2011). The lactating dams were fed the VDS diet because the enhanced calcium absorption that occurs with pregnancy goes back to the nonpregnant state after parturition, thus putting vitamin D-deficient dams at great risk for physiological stress due to disruptions in calcium homeostasis. Moreover, we have evidence that vitamin D-deficient female mice remain deficient for up to 3 weeks after returning to a VDS diet (Kent et al. 1991, Fudge \& Kovacs 2010, Belenchia et al. 2017).

After weaning, $A^{v y} / a$ and $a / a$ male offspring were randomly assigned to receive AIN-93G (LFD; Research 
Diets D10012G) or a high-fat diet (HFD, Research Diets D07101303B). We studied effects in males only, as males of this genotype and coat color are more likely to become obese and diabetic (Wolff et al. 1998, 1999). The treatment scheme creates a $2 \times 2 \times 2=8$ groups factorial treatment design (in utero environment (maternal VDS vs VDD) $\times$ genetic background $\left(A^{v y} / a\right.$ vs $a / a$ offspring) $\times$ postnatal environment (offspring lowvs high-fat diet)) (Fig. 1). This arrangement allowed us to examine the effects of maternal vitamin D status on offspring growth, adipose tissue health and other related metabolic parameters through two distinct models of excess adiposity (obesity): genetic $\left(A^{v y / a}\right)$ and postnatal environmental (high-fat diet-induced). Additionally, it provided us with intra-litter genotype controls $(a / a)$.

\section{Offspring growth, body composition and energy balance}

Offspring included in the study were weighed initially at weaning (21 days of age), and each week until study termination. The reason we did not weigh them prior to weaning was to minimize neonatal stress and potential maternal cannibalization. These data were used to plot growth curves. To pinpoint offspring growth patterns, the study period was divided into four distinct phases: neonatal (birth-3 weeks old), juvenile (3-7 weeks old), adolescence (7-11 weeks old) and adulthood (11-15 weeks old) (Fig. 1). Three-compartment body composition (lean tissue, fat tissue and water) was determined by EchoMRI at 19 weeks of age, just prior to study termination.

At 15-16 weeks of age, offspring energy expenditure was measured via indirect calorimetry to determine

A

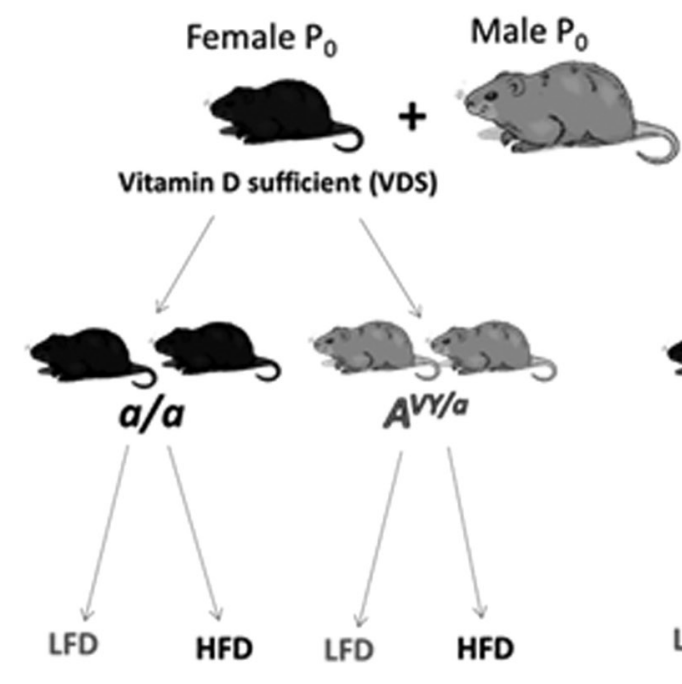

In utero environment

Vitamin D sufficient (VDS)
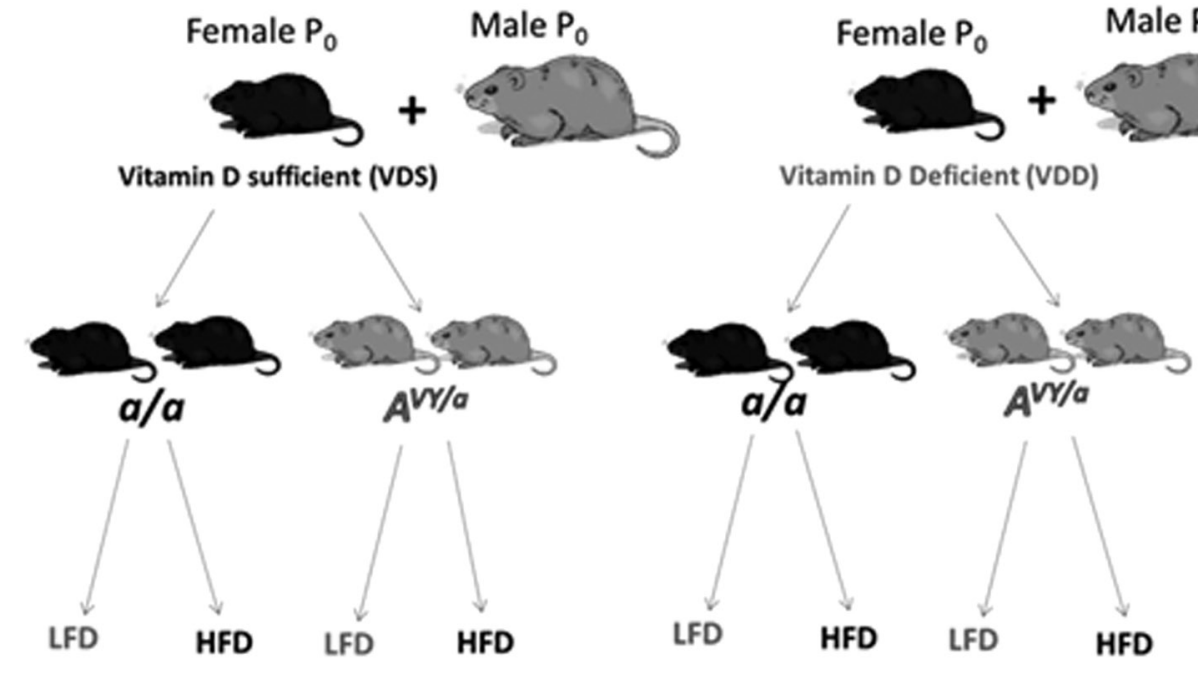

Genetic Background

Postnatal Environment

B

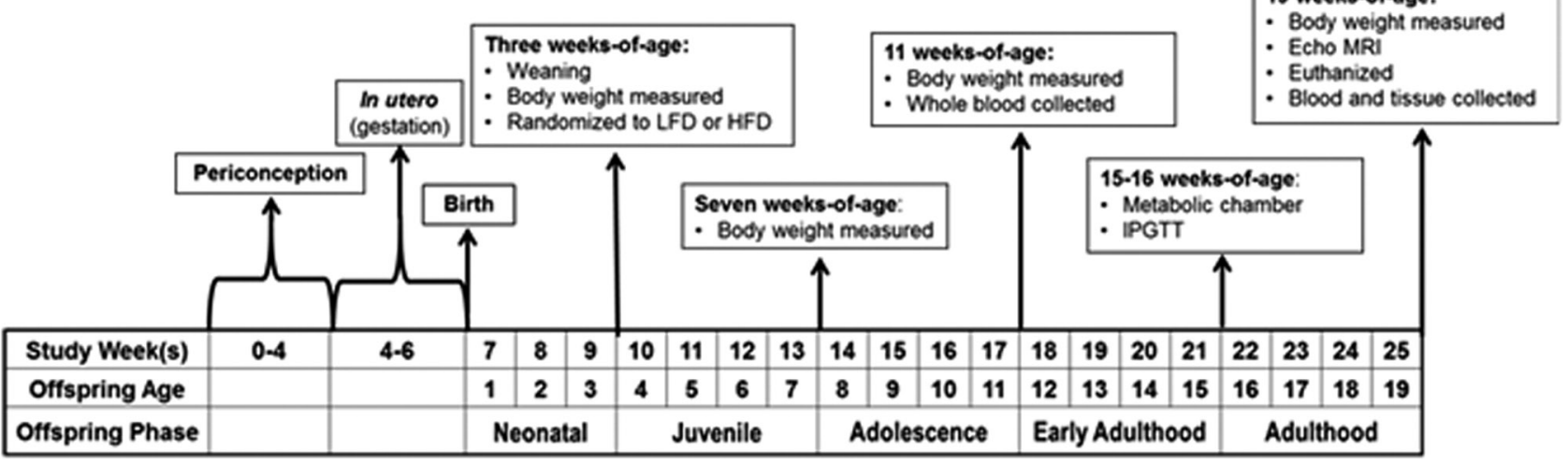

Figure 1

(A) General experimental design. Black mice represent a/a and yellow colored mice represent Avy/a. Female a/a (C57BL/6) mice were fed either a vitamin D-sufficient (VDS) or deficient (VDD) diet to generate vitamin D sufficient or deficient in utero environments for pups. Female ala were then bred with male $A^{v y / a}$ to generate litters containing mice of both genetic backgrounds. After weaning, offspring from each of these genetic backgrounds were randomized to receive either a high-fat diet (HFD) or low-fat diet (LFD) to create two distinct postnatal environments. (B) Experimental timeline for analyses and offspring age/life phase classifications of male $F_{1}$ offspring.

http://joe.endocrinology-journals.org DOI: 10.1530/JOE-17-0015
๑) 2017 Society for Endocrinology Printed in Great Britain
Published by Bioscientifica Ltd 
effects of each of its components (energy intake and expenditure) on growth and body composition. Mice from each group were individually adapted to metabolic chambers (Promethion; Sable Systems, Las Vegas, Nevada) for a minimum of $24 \mathrm{~h}$. Afterward, all parameters were measured for 48 consecutive hours.

\section{Vitamin D status and circulating cytokines in offspring}

Whole blood was collected from offspring at 11 (saphenous vein) and 19 (cardiac puncture) weeks of age, representing mid- and endpoints of the study, and separated by centrifugation, and then stored at $-80^{\circ} \mathrm{C}$ until analysis. Serum concentrations of $25(\mathrm{OH}) \mathrm{D}$ were measured using ELISA (Eagle Biosciences; Nashua, NH, USA; range $10-300 \mathrm{nmol} / \mathrm{L}$, intra-assay $\mathrm{CV}=4.2 \%$ ), following the manufacturer's protocol. Serum leptin, adiponectin, interleukine-6 (IL6) and tumor necrosis factor-alpha (TNFA) were measured using a commercially available MILLIPLEX Kit that simultaneously measures all of these cytokines (Customized Mouse Adipokine Panel; EMD Millipore; intra-assay CV 5.5\%).

\section{Serum glucose assessments}

At 15-16 weeks of age, following a six-hour fast ( 04:0010:00 h), blood was drawn from the saphenous vein to measure fasting glucose (AlphaTRAK 2 glucocometer; Zoetis; Florham Park, NJ, USA). Fasting intraperitoneal glucose tolerance tests (IPGTT) were then performed by giving mice an intraperitoneal injection of $20 \%$ glucose solution equivalent to $2.0 / \mathrm{kg}$ of body weight. Glucose levels were remeasured at 15, 30, 60 and $120 \mathrm{~min}$. Glucose disposal was calculated by determining the area under curve (AUC) by trapezoidal method on a time $\times$ concentration plot.

\section{Adipose tissue collection}

At study termination (19 weeks of age), mice were euthanized. Perigonadal (PGAT) and subcutaneous (SQAT; inguinal) adipose pads were excised and weighed. Both fat pads were dissected in half, with one-half fixed in $4 \%$ paraformaldehyde solution (for histological analysis) and the remaining half flash-frozen in liquid nitrogen and stored at $-80^{\circ} \mathrm{C}$ for later RNA extraction (PGAT fat pad only). All excisions were performed by the same individual to minimize technical variation.

\section{Perigonadal adipose tissue histology}

Fixed samples of PGAT were sent to the MU Veterinary Diagnostic Lab, where they were paraffin-embedded, sectioned $(4-5 \mu \mathrm{m})$ and stained with hematoxylin and eosin (H\&E). Six to eight fields per sample were acquired with an Olympus DX51 light microscope with the $40 \times$ objective lens, from which a minimum of 100 cells were measured using ImageJ software as described previously. Briefly, captured images were processed using binary, gray mode and threshold commands. Adipocytes for which a complete border was not distinguishable (e.g. those on the edge of the frame) were deselected. From the processed images, mean adipocyte area was determined using the 'measure all' command (NIH). This and other similar methods have been previously demonstrated to provide a validated estimate of mean adipocyte size and morphology (Yamauchi et al. 2001, Chen \& Farese 2002, Wueest et al. 2012, Osman et al. 2013, Parlee et al. 2014).

\section{Perigonadal adipose tissue RNA isolation, cDNA synthesis and gene expression analysis}

RNA was isolated from $40 \mathrm{mg}$ of PGAT using the AllPrep DNA/RNA/miRNA Microkit (Qiagen). Genomic DNA (gDNA) from isolated RNA was removed using DNAse 1 (Qiagen). RNA purity and concentration were assessed by $260 / 280$ and $260 / 230$ readings using a NanoDrop Spectrophotometer (Thermo Fisher Scientific), and RNA integrity was determined by fragment analyzer (ABI 3730xl DNA Analyzer, Applied Biosystem). First-strand cDNA was prepared using $40 \mu \mathrm{g}$ of perigonadal adipose tissue using the QuantiTect Reverse Transcription kit (Qiagen).

Real-time quantitative PCR (qPCR) was performed, using template cDNA, QuantiTect SYBR green master mix (Qiagen) and mouse-specific primers (Table 2). Forward and reverse primer pairs for Vdr, Pparg, Lep, Adipoq, Cebpa, and hypoxanthinephosphoribosyl-transferase-1 (Hprt1, reference control) were designed to amplify fragments spanning more than one exon using the NCBI primer design tool and confirmed using Primer3Plus. Primers were acquired from IDT (Coralville, IA, USA).

Reactions were run on the ABI 7500 (Applied Biosystems) with the following conditions: Polymerase activation: $15 \mathrm{~min}$ at $95^{\circ} \mathrm{C}$, followed by 40 cycles of (a) denaturation $15 \mathrm{~s}$ at $94^{\circ} \mathrm{C}$, (b) annealing: $35 \mathrm{~s}$ at $56^{\circ} \mathrm{C}$ and (c) extension $35 \mathrm{~s}$ at $72^{\circ} \mathrm{C}$ (data acquisition step). A dissociation melt curve analysis was performed from $60^{\circ} \mathrm{C}$ to $95^{\circ} \mathrm{C}$ to verify the specificity of the PCR products.

Published by Bioscientifica Ltd. 
Table 2 Primer sequences used in the real-time quantitative PCR analysis.

\begin{tabular}{|c|c|c|c|}
\hline Name & Sequence $\left(5^{\prime} \rightarrow 3^{\prime}\right)$ & $\begin{array}{l}\text { GenBank } \\
\text { accession }\end{array}$ & $\begin{array}{c}\text { NCBI } \\
\text { gene ID }\end{array}$ \\
\hline Pparg2 F & TCGCTGATGCACTGCCTATG & NM_011146.3 & 19,016 \\
\hline Pparg2 R & GAGAGGTCCACAGAGCTGATT & & \\
\hline$V d r F$ & GTGCAGCGTAAGCGAGAGAT & NM_009504.4 & 22 \\
\hline $\operatorname{Vdr} R$ & TGTGCTGTTG & & \\
\hline Cepba F & TTCGGGTCGCTGGATCTCTA & NM_007678.3 & 12,606 \\
\hline Cepba $R$ & TCAAGGAGAAACCACCACGG & & \\
\hline Lep $F$ & TTCACACACGCAGTCGGTATC & NM_008493.3 & 16,846 \\
\hline Lep $R$ & GGCTC & & \\
\hline adipoq $F$ & GTTCCCAATGTACCCATTCGC & NM_009605 & 11,450 \\
\hline $\operatorname{adipoq} R$ & TGTTGCAGTAGAACTTGCCAG & & \\
\hline Hprt1 F & GTTGGGCTTACCTCATGCT & NM_013556 & 15,452 \\
\hline Hprt1 R & TCATCGCTAACACGACGCT & & \\
\hline Gapdh F & TGGCCTTCCGTGTTCCTAC & NM_008084 & 14,433 \\
\hline Gapdh $R$ & GAGTTGCTGTTGAAGTCGCA & & \\
\hline
\end{tabular}

Reaction data were analyzed using the comparative cycle threshold method. A serial dilution 'pool lane' that comprised equal amounts of template cDNA from each sample was set up to compare reaction efficiencies.

Normalized expression values $(\Delta \mathrm{CT})$ were determined by subtracting the detected CT value of the target gene from the detected CT value of the housekeeping gene (Hprt1). These values are such that an increase in $\Delta \mathrm{CT}$ corresponds to an increase in the relative expression. $\Delta \mathrm{CT}$ linear model coefficients represent log-fold changes in gene expression and allow for pairwise comparisons.

\section{Statistical analysis}

There were three factors with two levels each, in utero environment (two levels reflecting maternal vitamin D status; VDD or VDS), genetic background (two levels of offspring genotype; $a / a$ or $A^{v y} / a$ ), and postnatal environment (two levels of offspring diet; LFD or HFD), yielding eight combinations. The general experimental design was a split-plot in space, with in utero environment serving as the main plot; and genetic background, postnatal environment and all possible interactions serving as subplots. As more than one offspring per litter was tested, we controlled for the possible confounding effect of litter by assigning a unique nominal value for each dam-sire pairing; offspring nested within litter was used as a random factor in all subsequent ANOVAs. For all dependent variables, the model included the main effects in utero environment, genetic background, offspring diet, and all possible two- and three-way interactions of these factors.
Since the primary research question involved the effects of in utero environment (maternal vitamin D status), for some outcomes (inflammatory markers and gene expression), data for the groups with the combined obesogenic models ( $A^{v y} / a$ mice fed HFD) were not collected. In these experiments, genetic background and postnatal environment were combined into one factor, 'offspring group.' This combined factor had three levels of interest, $\mathrm{LFD} \times a / a, \mathrm{HFD} \times a / a$ and $\mathrm{LFD} \times A^{v y} / a$, yielding a $2 \times 3$ factorial design. In such analyses, the model included the fixed effects of in utero environment (two levels; VDS and VDD), the aforementioned 'offspring groups,' and the in utero environment*offspring group interaction.

All data were checked for normality using the Shapiro-Wilke test. Non-normally distributed data were log-transformed for analysis and subsequently back-transformed for data presentation. Two-way ANOVA was performed using PROC GLIMMIX. Litter within in utero environment was used as the denominator for the main plot and 'litter' within in utero environment*genetic background*postnatal environment was used as the denominator for all subplots. Fisher's protected least significant difference (LSD) was used to make all pairwise comparisons. All data are expressed as least square means \pm s.D. in text and least square means \pm S.E.M. in tables/figures, with $P<0.05$ considered significant for main and simple main effects.

Unadjusted Pearson correlation coefficients $(r)$ were determined to assess the relationship between offspring weight at weaning, juvenile weight gain and adipose distribution. Correlations between PGAT gene expression and the aforementioned variables were also determined. All correlation analyses were carried out using PROC REG (SAS 9.4). $P<0.05$ was considered significant.

\section{Results}

\section{Pregnancy and litter characteristics}

There were no differences between the VDD and VDS in utero environment groups in gestation length $(20.2 \pm 0.6$ vs $19.9 \pm 0.7 ; P=0.73)$ or litter size $(7.8 \pm 1.2$ vs $7.2 \pm 1.9$; $P=0.37$; Table 3 ). Offspring sex ratio did not differ between the two groups (male pups: 53 vs 55\%, respectively, $P=0.93)$ nor were there any differences in percentage of $A^{v y / a}$ offspring (47.9\%, respectively, $\left.P=0.81\right)$.
๑ 2017 Society for Endocrinology Printed in Great Britain
Published by Bioscientifica Ltd 
Table 3 Litter characteristics of in utero environment (maternal vitamin D deficiency) groups.

\begin{tabular}{|c|c|c|c|}
\hline Parameter & VDS & VDD & $P$ Value \\
\hline Pups per litter ${ }^{a}$ mean \pm & $7.8 \pm 0.4$ & $7.3 \pm 0.7$ & 0.37 \\
\hline Male (\%) & 53 & 55 & 0.93 \\
\hline a/a $(\%)$ & 48.2 & 47.9 & 0.81 \\
\hline$A^{v y / a}(\%)^{b}$ & 51.7 & 52.1 & 0.85 \\
\hline Gestation length (d)a & 20.2 & 19.9 & 0.73 \\
\hline
\end{tabular}

aTogether, the lack of difference in litter size and gestation length demonstrate that VDD dams did not demonstrate dystocia or birthing difficulty (i.e. calcium-dependent processes were not disrupted); brepresents full range of coat colors that span from pseudo-agouti to yellow. In the current study, only yellow male offspring were examined. ala, non-agouti (c57BL/6); Avy/a, viable yellow agouti; VDD, vitamin D deficient; VDS, vitamin D sufficient.

\section{Offspring vitamin D status}

No differences existed in serum $25(\mathrm{OH}) \mathrm{D}$, at either 11 or 19 weeks of age, in the offspring born to VDD dams vs VDS dams $(63.7 \pm 10.8$ vs $64.8 \pm 10.4 \mathrm{nmol} / \mathrm{L}, P=0.79$ and $65.6 \pm 13.4$ vs $65.8 \pm 11.1 \mathrm{nmol} / \mathrm{L}, P=0.83$, respectively). However, mean serum 25(OH)D levels were lower in both obesogenic offspring models $\left(A^{v y} / a=47.4 \pm 12.1 \mathrm{nmol} / \mathrm{L}\right.$ and $\mathrm{HFD}=48.9 \pm 14.2 \mathrm{nmol} / \mathrm{L} ; \quad P=0.72)$ than nonobesogenic offspring.

\section{Offspring growth and energy balance}

Mice born to VDD dams weighed less at weaning than those born to VDS dams $(9.94 \pm 0.68 \mathrm{~g}$ vs $10.41 \pm 0.62 \mathrm{~g}$, $P=0.014$; not shown). There was a significant three-

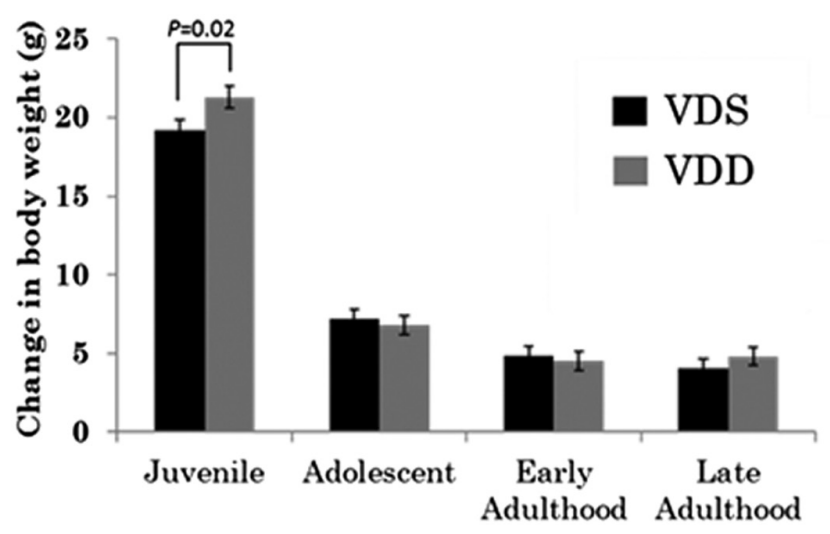

Figure 2

Body weight (BW) changes in offspring during various life phases: juvenile (weaning through 7 weeks of age), adolescent (7 through 11 weeks of age), early adulthood (11 through 15 weeks of age) and adulthood (15 through 19 weeks of age). Different shaded bars represent different in utero environment groups (i.e., maternal vitamin D status, vitamin D deficient (VDD) or sufficient (VDS)). Data are presented as marginal mean \pm S.E.M. way interaction between in utero environment, genetic background and postnatal environment on overall offspring growth curves from weaning to 19 weeks of age $(P=0.002$, respectively; not shown). The simple effects of this interaction revealed that offspring of VDD dams were more susceptible to genetically induced than HFD-induced obesity. Furthermore, offspring born to VDD dams gained more weight during the juvenile period (three to seven weeks of age; $\Delta+21.2 \mathrm{~g}$ vs $+19.1 \mathrm{~g}, P=0.003$; Fig. 2), while there was no effect of maternal vitamin $D$ status on weight gain during any other period of life.

In utero environment (maternal vitamin $\mathrm{D}$ status) had no effect on overall feed intake (g/day; $P=0.138)$ or total energy intake (kcal/day; $P=0.105$; not shown). No significant main or interaction effects were evident for any of the three factors (in utero environment, genetic background and postnatal environment) on energy expenditure or spontaneous physical activity. $A^{v y / a}$ mice consumed significantly greater amounts of feed than $a / a$ mice $(3.3 \pm 0.4$ vs $2.7 \pm 0.4 \mathrm{~g} /$ day; $P=0.0461)$. Due to the enhanced caloric density of the HFD and hyperphagic phenotype of $A^{v y} / a$ mice, both the $A^{v y} / a(14.7 \pm 1.5 \mathrm{kcal}$, $P=0.033)$ and HFD $(14.9 \pm 2.1 \mathrm{kcal}, P=0.044)$ groups consumed significantly more total energy than nonobesogenic counterparts (not shown).

\section{Total, percent and distribution of body fat}

A significant three-way interaction existed between in utero environment, genetic background and postnatal environment on total fat mass $(P=0.026$, not shown). Determination of the simple effects revealed that in utero environment (maternal vitamin $\mathrm{D}$ status) was not responsible for this interaction at any level of genetic background $\times$ postnatal environment. There were no significant main or interaction effects of in utero environment on body fat percentage. Both obesogenic groups ( $A^{v y / a}$ and HFD) had body fat percentages that were significantly greater than non-obesogenic groups $(47.2 \pm 10.4$ vs $29.8 \pm 10.1 \% ; P<0.001$; and $45.0 \pm 11.4$ vs $32.0 \pm 9.45 \%, P<0.001$, respectively).

In utero environment did not significantly affect absolute or relative SQAT pad weights of offspring ( $P=0.113$ and $P=0.366$; not shown). However, there was a significant interaction between in utero environment and genetic background on absolute PGAT (visceral) weight $(P=0.022)$, wherein in utero VDD resulted in significantly larger PGAT pads only in $A^{v y} / a$ offspring $(2.13 \pm 0.32$ vs $1.76 \pm 0.36$ g; $P=0.006$; Fig. 3$)$. Although the effect was

Published by Bioscientifica Ltd. 

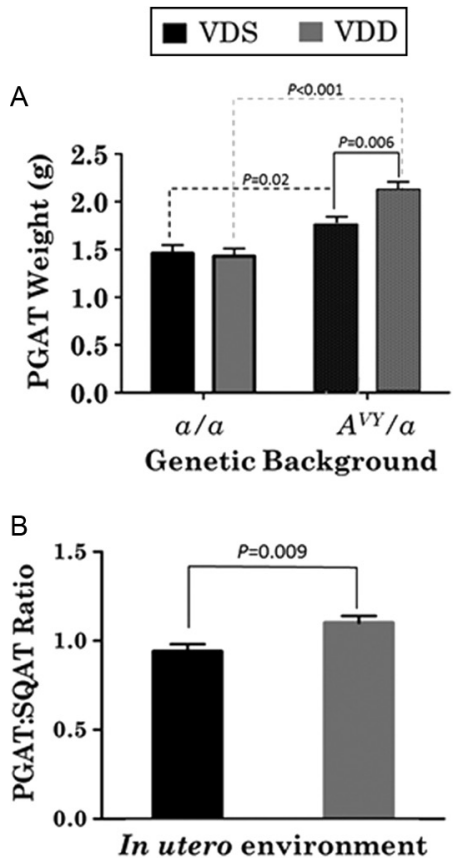

Figure 3

(A) Perigonadal adipose pad (PGAT) weights. Different shaded bars represent different in utero environment groups. (B) Ratio of perigonadal (PGAT) to subcutaneous (SQAT) adipose tissue weights. Different shaded bars represent different in utero environment groups (i.e., maternal vitamin $\mathrm{D}$ status, vitamin $\mathrm{D}$ deficient (VDD) or sufficient (VDS)). Data are presented as marginal mean \pm S.E.M.

similar in direction for the relative (to body weight) weight of PGAT pads, it did not reach statistical significance, $(P=0.08$; not shown). Both genetic background and postnatal environment had a significant effect on SQAT pad weight, with both obesogenic groups ( $A$ vy/a and HFD) having significantly larger SQAT pads (both $P<0.0001$; not shown). A main effect of in utero environment on the ratio of PGAT to SQAT existed, wherein offspring gestated in a VDD in utero environment had a significantly greater ratio of PGAT to SQAT $(1.1 \pm 0.19$ vs $0.94 \pm 0.21$; $P=0.012$; Fig. 3).

\section{Blood glucose disposal}

Baseline fasting glucose concentrations indicated no main or interaction effects of in utero environment (not shown). Likewise, the circulating glucose response to glucose load was not statistically significant between the maternal VDS and VDD groups (not shown). There was a significant interaction effect of genetic background and postnatal environment, wherein mice with combined obesogenic factors (HFD-fed and $A^{v y} / a$ ) had elevated fasting glucose concentrations and impaired glycemic response regardless of in utero environment (not shown).

\section{Adipocyte histology and circulating markers of adipocyte health}

There was a significant two-way interaction between in utero environment and postnatal environment $(P=0.039)$, wherein HFD-induced PGAT adipocyte hypertrophy was greater in mice gestated in a VDDdeficient intrauterine environment than in those born from a VDS dams $(P=0.017$; Fig. 4). Adipocytes from $A^{v y / a}$ offspring were significantly larger than those from non-obesogenic groups $(P=0.002)$. However, in utero
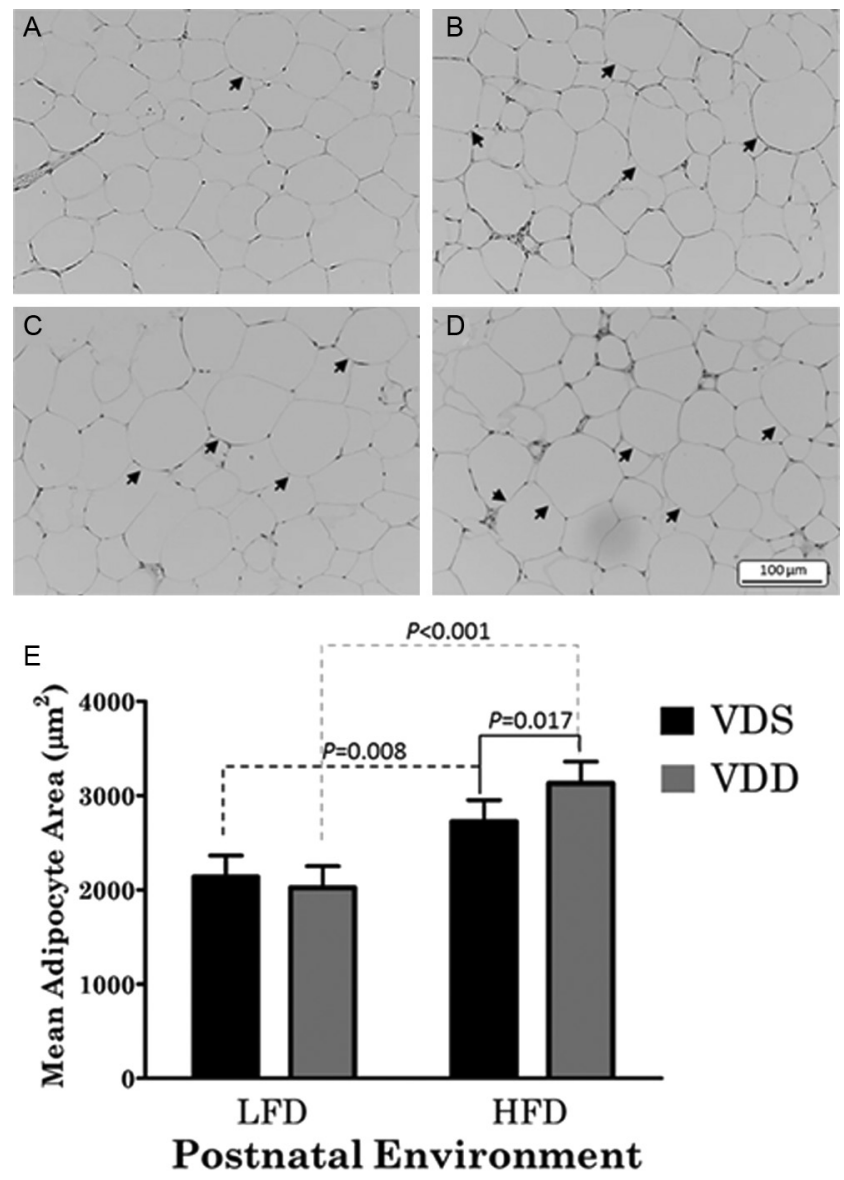

Figure 4

( $A, B, C$ and D) Micrographs of representative H\&E-stained perigonadal adipose tissue samples from vitamin $D$ sufficient-low fat (VDS-LF), vitamin D sufficient-high fat (VDS-HF), vitamin D deficient-low fat (VDD-LF) and vitamin $\mathrm{D}$ deficient-high fat (VDD-HF) offspring groups, respectively. Arrows indicate larger adipocytes (hypertrophied) compared to the mean of the VDS-LF group. All images were obtained from a/a mice within the respective in utero (maternal vitamin $D$ status) and postnatal environment combination (low- or high-fat diet). (E) Mean perigonadal adipocyte area. Images were captured with a $40 \times$ objective lens. Mean values for each sample were obtained from at least 100 cells taken from a minimum of six fields of view. Different shaded bars represent different in utero environment groups (i.e., maternal vitamin $D$ status, vitamin $D$ deficient (VDD) or sufficient (VDS)).

Published by Bioscientifica Ltd 
Table 4 mRNA expression in perigonadal adipose tissue of mice offspring at 19 weeks of agea.

\begin{tabular}{|c|c|c|c|c|c|c|}
\hline & \multicolumn{6}{|c|}{ In utero environment and obesogenic group } \\
\hline & VDS & VDD & VDS & VDD & VDS & VDD \\
\hline & a/a-LFD & a/a-LFD & $A^{v y / a} \mathrm{LFD}$ & Avy/a LFD & a/a-HFD & a/a-HFD \\
\hline Pparg & $9.0 \pm 0.5$ & $6.0 \pm 0.6^{b}$ & $7.9 \pm 0.6$ & $5.7 \pm 0.7 \mathrm{~b}$ & $6.3 \pm 0.5$ & $6.6 \pm 0.4$ \\
\hline Cebpa & $5.7 \pm 1.0$ & $4.0 \pm 0.9$ & $4.2 \pm 1.0$ & $3.0 \pm 0.9$ & $3.5 \pm 0.9$ & $3.4 \pm 0.8$ \\
\hline$V d r$ & $12.2 \pm 0.6$ & $10.8 \pm 0.5$ & $12.3 \pm 0.6$ & $11.3 \pm 0.6$ & $11.4 \pm 0.8$ & $11.7 \pm 0.6$ \\
\hline Lep & $6.3 \pm 0.8$ & $4.8 \pm 0.8$ & $4.8 \pm 0.9$ & $3.0 \pm 0.6$ & $3.9 \pm 0.8$ & $3.4 \pm 0.4$ \\
\hline Adip & $0.77 \pm 0.4$ & $0.84 \pm 0.4$ & $0.18 \pm 0.3$ & $0.67 \pm 0.4$ & $0.61 \pm 0.3$ & $0.39 \pm 0.5$ \\
\hline
\end{tabular}

aData are presented as means \pm S.E.M.; value shown is $\Delta \mathrm{Ct}$ (gene of interest-housekeeping gene), therefore lower values indicate higher expression; bsignificantly different than value to the left (between in utero environment; $P<0.05$ ).

a/a, non-agouti (c57BL/6); Adip, adiponectin; Avy/a, viable yellow agouti; Cebpa, CCAAT/enhancer-binding protein-alpha; HFD, high-fat diet; IU, in utero; Lep, leptin; LFD, low-fat diet; Pparg, peroxisome proliferator-activated receptor gamma; OG, offspring group (genetic background $\times$ postnatal environment); VDD, vitamin D deficient; Vdr, vitamin D receptor; VDS, vitamin D sufficient.

environment did not similarly affect adipocyte area in $A^{\text {vy } / a}$ offspring ( $P=0.26$; not shown).

There were no main or interaction effects of in utero environment on the circulating concentrations of IL6 or TNFa $(P=0.425$ and $P=0.589$, respectively; not shown). Similarly, there were no main or interaction effects involving in utero environment on circulating leptin concentrations $(P=0.451$; not shown). However, there was a main effect of offspring group on leptin, wherein $A^{v y} / a(15,854 \pm 3320 \mathrm{pg} / \mathrm{mL})$, but not HFD-fed $(12,934 \pm 4656 \mathrm{pg} / \mathrm{mL})$ offspring, had greater circulating concentrations than $a / a(10,742 \pm 3235 \mathrm{pg} / \mathrm{mL} ; P=0.007$ and $P=0.173$, respectively; not shown) mice.

\section{Perigonadal adipose tissue gene expression}

There was a significant main effect of in utero environment on Pparg mRNA expression, wherein mice born to VDD dams had 3.7-fold increase over those born to VDS dams ( $P=0.008$; Table 4$)$. The interaction between in utero environment and offspring group was not significant $(P=0.058)$; however, visual examination of the interactions called for further analysis. In response to in utero VDD (vs VDS), Pparg expression was upregulated in the PGAT of both $a / a(6.7$-fold increase, $P=0.006)$ and $A^{v y / a}$ mice fed a low-fat diet (4.2-fold increase, $P=0.02$ ), but not HFD-fed $a / a$ mice. However, in utero environment did not significantly affect the relative expression levels of $V d r(P=0.946)$, Lep $(P=0.121)$, Adipoq $(P=0.669)$ or Cebpa $(P=0.092)$ mRNA in PGAT.

\section{Correlations between body weight and adiposity}

There was a weak but significant negative correlation between weight at weaning and the ratio of PGAT:SQAT $(r=-0.28, P=0.038$; Table 5).

\section{Correlations between PGAT gene expression and phenotypic assessments}

Among the genes analyzed from PGAT, the expression levels of Pparg $(r=-0.43, P=0.009)$, Cebpa $(r=-0.38$, $P=0.025)$ and $V d r(r=-0.42, P=0.01)$ were all positively associated with PGAT:SQAT ratio (Table 6). However, while significant, the strength of these relationships was moderate. Likewise, moderate but significant associations

Table 5 Correlations of body weight and adipose tissue mass measurements of mice offspring at 19 weeks of agea.

\begin{tabular}{|c|c|c|c|c|c|}
\hline & & Weight at weaning & Juvenile weight gain & Total fat mass & PGAT:SQAT ratio \\
\hline \multirow[t]{2}{*}{ Weight at weaning } & $R$ & - & $n s^{b}$ & ns & -0.28 \\
\hline & $P$ value & - & Ns & ns & 0.038 \\
\hline \multirow[t]{2}{*}{ Juvenile weight gain } & $R$ & ns & - & 0.84 & ns \\
\hline & $P$ value & ns & - & $<0.001$ & ns \\
\hline \multirow[t]{2}{*}{ Total fat mass } & $R$ & ns & 0.84 & - & 0.84 \\
\hline & $P$ value & ns & $<0.001$ & - & $<0.001$ \\
\hline \multirow[t]{2}{*}{ PGAT:SQAT ratio } & $R$ & -0.28 & Ns & ns & - \\
\hline & $P$ value & 0.038 & Ns & ns & - \\
\hline
\end{tabular}

aData are $r$-unadjusted Pearson correlation coefficients; $P$ value represents the significance of the correlation; bns, non-significant correlation $(P>0.05)$; bold values indicate statistical significance, $P<0.05$. PGAT, perigonadal adipose tissue; SQAT, subcutaneous adipose tissue.

http://joe.endocrinology-journals.org DOI: 10.1530/JOE-17-0015 (c) 2017 Society for Endocrinology Printed in Great Britain
Published by Bioscientifica Ltd. 
Table 6 Correlation of perigonadal adipose tissue gene expression with various phenotypic assessments of mice offspring body fat at 19 weeks of agea.

\begin{tabular}{|c|c|c|c|c|c|c|}
\hline & & Total fat mass & Perigonadal pad weight & Subcutaneous pad weight & PGAT:SQAT ratio & Circulating leptin \\
\hline \multirow[t]{2}{*}{ Pparg } & $R$ & $n s^{b}$ & 0.34 & Ns & 0.43 & 0.42 \\
\hline & $P$ value & ns & 0.043 & Ns & 0.009 & 0.005 \\
\hline \multirow[t]{2}{*}{ Cebpa } & $R$ & ns & 0.43 & Ns & 0.38 & ns \\
\hline & $P$ value & ns & 0.009 & Ns & 0.025 & ns \\
\hline \multirow[t]{2}{*}{$V d r$} & $R$ & ns & Ns & Ns & 0.42 & ns \\
\hline & $P$ value & - & Ns & Ns & 0.010 & ns \\
\hline \multirow[t]{2}{*}{ Lep } & $R$ & 0.42 & 0.48 & Ns & ns & 0.46 \\
\hline & $P$ value & 0.044 & 0.003 & Ns & ns & 0.007 \\
\hline \multirow[t]{2}{*}{ Adip } & $R$ & ns & Ns & Ns & ns & ns \\
\hline & $P$ value & ns & Ns & Ns & ns & ns \\
\hline
\end{tabular}

aData are $r$-unadjusted Pearson correlation coefficients; $P$ value represents the significance of the correlation; bns, non-significant correlation $(P>0.05)$; bold values indicate statistical significance, $P<0.05$. Adip, adiponectin; Cebpa, CCAAT/enhancer-binding protein-alpha; Lep, leptin; PGAT, perigonadal adipose tissue; Ppar, peroxisome proliferator-activated receptor gamma; SQAT, subcutaneous adipose tissue; Vdr, vitamin D receptor.

existed between PGAT Pparg expression and PGAT weight $(r=0.34, P<0.043)$. PGAT Lep expression was positively associated with total fat mass $(r=-0.42, \quad P=0.04)$, PGAT mass $(r=-0.48, P=0.003)$ and circulating leptin concentration ( $r=-0.46, P=0.006$; Table 6).

\section{Discussion}

Vitamin D is a key player in differentiation of mesenchymal stem cells into several cell types including adipocytes (Narvaez et al. 2013, Valle et al. 2016). However, there is a gap in our understanding of the consequences of maternal VDD during pregnancy on adipose tissue development and related parameters of metabolic health in offspring. Our results indicate that male murine offspring gestated in a VDD environment experience: fetal growth restriction, accelerated growth in early life, larger visceral body fat pads and greater susceptibility to HFD-induced adipocyte hypertrophy. Moreover, the fetal growth restriction and accelerated juvenile weight gain are associated with adverse metabolic-health-related phenotypic outcomes in adulthood (greater ratio of visceral to subcutaneous fat distribution and adult body fat mass, respectively); and these observations are associated with greater Pparg expression in visceral adipose tissue.

There is scientific support for a relationship between maternal VDD and impaired fetal growth (Bodnar et al. 2010, Gernand et al. 2014). Epidemiological studies show a strong correlation between maternal VDD and fetal growth restriction in several cohorts (Leffelaar et al. 2010, Walsh et al. 2012). Conversely, prospective studies have yielded conflicting results that may be attributed to the varying degrees of deficiency and when during embryonic development the deficiency is experienced (Hashemipour etal.2014, Park etal. 2014, Reichetzeder etal. 2014). In the present study, maternal VDD resulted in impaired fetal growth with apparent 'catch-up' juvenile weight gain. Offspring born to these dams weighed $~ 5 \%$ less than those to controls at weaning regardless of genetic background $\left(A^{v y / a}\right.$ or $\left.a / a\right)$ and gained $\sim 11 \%$ more weight in the first four weeks after weaning. Differences in body weight at weaning suggest that they weighed less at birth and/or gained less in the first three weeks post parturition. However, we are unaware of any evidence demonstrating delayed neonatal growth and therefore, we believe the rapid weight gain observed in these mice during the first four weeks post weaning suggests that fetal growth restriction with VDD is more likely. Although maternal VDD did not affect total fat mass or body composition of adult offspring in this rodent study; the finding of a positive correlation between juvenile weight gain and total adult fat mass, even when corrected for genetic background and postnatal environment, is interesting as accelerated weight gain during the neonatal period in humans is associated with adiposity in adulthood (Stettler et al. 2003, 2005, Breij et al. 2014).

Human studies have indicated that accumulation of fat in visceral adipose depots poses a greater risk to metabolic health than that in subcutaneous sites (Despres et al. 1990, Bouchard et al. 1993, Despres 2001, Landsberg 2008, Lee et al. 2013), possibly more so than excess total fat mass. Many factors influence the location of adipose deposition and its metabolic actions (Lachance \& Page 1953, Pascot et al. 1999), and there is some evidence for vitamin $\mathrm{D}$ to be an important mediator. For example, in a rodent experiment, $\mathrm{F}_{1}$ progeny born to VDD dams were shown to have more total fat and visceral fat 
(Nascimento et al. 2013). Our study extends these findings by showing that although total fat mass was unaffected, a greater visceral-to-subcutaneous fat ratio of adult offspring developed in the VDD in utero environment, independent of genetic background or postnatal environment. This is noteworthy as it indicates that exposure to VDD in utero either directly or indirectly influences the development of body fat toward a more unfavorable (in terms of metabolic health) distribution.

The genes for the vitamin $\mathrm{D}$ receptor (VDR) and vitamin D-metabolizing enzymes are located in animal and human adipocytes; and both the active form, 1,25 dihydroxyvitamin $\mathrm{D}\left(1,25[\mathrm{OH}]_{2} \mathrm{D}\right)$, and the parent molecule, vitamin $\mathrm{D}$, are known to influence several key adipogenic genes and transcription factors as well as lipid accumulation (Ding et al. 2012, Zoico et al. 2014). Even so, the specific function of vitamin $\mathrm{D}$ in the adipogenic process remains equivocal, and often contradictory, with studies showing both stimulation and inhibition of adipogenesis (Mutt et al. 2014). With the aid of two obesogenic models, we were able to explore the interactive effects of intrauterine vitamin D availability with both postnatal environment and genetic background on the development of adiposity and related metabolic health measures in offspring. Our data reveal that maternal VDD exacerbates select metabolic parameters differently depending on the obesity model (Fig. 5). Offspring gestated in a VDD environment demonstrated greater
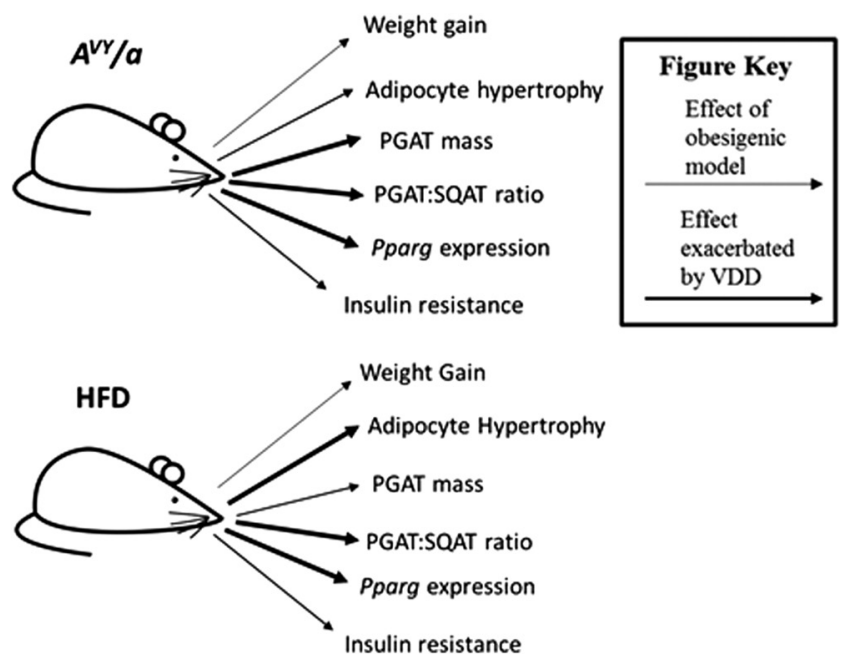

Figure 5

Summary of observed metabolic effects of both offspring obesogenic models, i.e., genetic ( $A^{v y / a}$ ) and diet-induced (HFD). Arrows indicate a significant difference between obesogenic vs non-obesogenic groups for specific measurements $(P<0.05)$. Bold arrows indicate an effect that was exacerbated in offspring subjected to a vitamin D deficiency (VDD) in utero environment. susceptibility to HFD-induced adipocyte hypertrophy. Conversely, intrauterine VDD only affected the distribution of adipose tissue in the genetic model of obesity, with $A^{v y} / a$, but not HFD-fed mice possessing larger visceral fat pads.

Maternal VDD has been associated with autoimmune disease in offspring (Erkkola et al. 2011), and multiple studies have demonstrated that offspring gestated in a VDD intrauterine environment are more susceptible to HFD-induced inflammation (Villa et al. 2016). We did not detect any effects of in utero VDD on either circulating inflammatory marker, TNFA or IL6. However, neither of our obesogenic models demonstrated elevated levels of these markers, and thus it is possible that the study was not carried out for long time to induce significant immunological responses. Circulating leptin concentration, which is highly correlated with adipose mass/size and insulin response, was significantly greater in our genetic model of obesity but not in our HFDinduced model of obesity. Both obesogenic models had altered glucose homeostasis and glycemic responses, while the in utero environment (maternal VDD) had neither effect on circulating leptin concentration nor on glucose disposal. This is not surprising since in utero VDD did not affect overall fat mass of the offspring. Furthermore, subcutaneous adipose tissue has been shown to produce more leptin than visceral adipose tissue and in the current study, in utero VDD had greater effect on visceral (PGAT) mass.

The nuclear receptor PPARG plays integral roles in both adipogenesis and lipid storage (Spiegelman et al. 1997, Rosen \& Spiegelman 2000, Lazar 2002). In this study, mice born to VDD dams had greater Pparg expression compared to offspring born to those developed in a VDS intrauterine environment. We have previously noted similar findings in non-obese mice born to VDD dams (Belenchia et al. 2016). Taken together, these PPARG expression observations in adult offspring provide evidence that maternal VDD during pregnancy has profound and long-lasting effects on adipose tissue and perhaps its metabolic activity. Although our study was limited by the lack of protein expression required to confirm an increase in the actual receptor, it is possible that modest increases in Pparg expression can cause significant downstream effects on adipose tissue mass.

Limitations of this investigation include restricting our analyses to male offspring. We chose this initial approach based on evidence that $A^{v y / a}$ males have greater metabolic disruptions than females (Klebig et al. 1995,

Published by Bioscientifica Ltd 
Wolff et al. 1999). Extending the phenotypic findings identified herein, our follow-up studies will include female $A^{v y} / a$ and $a / a$ offspring exposed to similar prenatal and postnatal diet alterations; and further exploration of the effects of in utero VDD on other metabolic tissues such as liver and muscle. Another limitation is the length of the study, which may have been too short to see changes in any of the secondary measures of metabolic health, such as inflammatory markers or glucose metabolism. Thus, in future work, we plan to expand assessments and extend study length in offspring exposed to in utero VDD to determine if these offspring are more susceptible to greater overall morbidity issues and decreased lifespan. Additionally, future works will aim to replicate the observed changes in adipose tissue distribution and adipocyte characterization using more concise methods, such as whole body densitometry and stereological assessment of adipocyte 3D structure. The use of other animal models (such as VDR knockout) might also provide additional insight into the pleotropic roles of vitamin D. Another future study would be to extend the maternal VDD through lactation to determine if more pronounced offspring effects are observed.

In conclusion, in utero VDD affects adipose tissue physiology and distribution into adulthood. Regardless of genetic background or postnatal environment, our results show that adult offspring gestated in a VDD environment gain more weight early in life, and have a more metabolically unfavorable fat distribution. Furthermore, the phenotypic response to in utero VDD is dissimilar between the two obesogenic models. These differences were associated with differences in Pparg mRNA expression in visceral fat, providing evidence that some metabolic disturbances of in utero VDD are mediated through direct effects on adipose tissue. These novel findings demonstrate that in utero VDD, an easily correctable but highly prevalent health concern, predisposes offspring to long-term adipose tissue consequences and possible adverse metabolic health complications.

\section{Declaration of interest}

The authors declare that there is no conflict of interest that could be perceived as prejudicing the impartiality of the research reported.

\section{Funding}

This work was funded by the Department of Nutrition \& Exercise Physiology, University of Missouri.

\section{Author contribution statement}

A M B, C A P, C S R developed the project idea and study design, and wrote the manuscript. A M B, the graduate student under CSR's and CAP's mentorship, and S A J were responsible for conducting the study and data acquisition. M E K and A M B performed the statistical analyses. All authors contributed to the final edits of the manuscript.

\section{References}

Almeras L, Eyles D, Benech P, Laffite D, Villard C, Patatian A, Boucraut J, Mackay-Sim A, McGrath J \& Feron F 2007 Developmental vitamin $\mathrm{D}$ deficiency alters brain protein expression in the adult rat: implications for neuropsychiatric disorders. Proteomics 7 769-780. (doi:10.1002/pmic.200600392)

Belenchia AM, Jones KL, Will M, Beversdorf DQ, Vieira-Potter V, Rosenfeld CS \& Peterson CA 2016 Maternal vitamin D deficiency during pregnancy affects expression of adipogenic-regulating genes peroxisome proliferator-activated receptor gamma (PPARgamma) and vitamin D receptor (VDR) in lean male mice offspring. European Journal of Nutrition [in press]. (doi:10.1007/s00394-016-1359-x)

Belenchia AM, Johnson SA, Kieschnick A, Rosenfeld CS \& Peterson CA 2017 Time-course for vitamin D depletion and repletion in reproductive age female $\mathrm{C} 57 / \mathrm{Bl} 6$ mice: prelude to understanding maternal vitamin D deficiency-induced DOHaD effects in offspring. Comparative Medicine [in press].

Bodnar LM, Catov JM, Zmuda JM, Cooper ME, Parrott MS, Roberts JM, Marazita ML \& Simhan HN 2010 Maternal serum 25-hydroxyvitamin D concentrations are associated with small-for-gestational age births in white women. Journal of Nutrition 140 999-1006. (doi:10.3945/ jn.109.119636)

Bouchard C, Despres JP \& Mauriege P 1993 Genetic and nongenetic determinants of regional fat distribution. Endocrine Reviews 14 72-93. (doi:10.1210/edrv-14-1-72)

Breij LM, Kerkhof GF \& Hokken-Koelega AC 2014 Accelerated infant weight gain and risk for nonalcoholic fatty liver disease in early adulthood. Journal of Clinical Endocrinology and Metabolism 99 1189-1195. (doi:10.1210/jc.2013-3199)

Burne TH, O'Loan J, Splatt K, Alexander S, McGrath JJ \& Eyles DW 2011 Developmental vitamin D (DVD) deficiency alters pupretrieval but not isolation-induced pup ultrasonic vocalizations in the rat. Physiological Behavior 102 201-204. (doi:10.1016/j. physbeh.2010.11.006)

Burris HH, Rifas-Shiman SL, Camargo CA Jr, Litonjua AA, Huh SY, Rich-Edwards JW \& Gillman MW 2012 Plasma 25-hydroxyvitamin D during pregnancy and small-for-gestational age in black and white infants. Annals of Epidemiology 22 581-586. (doi:10.1016/j. annepidem.2012.04.015)

Chen HC \& Farese RV Jr 2002 Determination of adipocyte size by computer image analysis. Journal of Lipid Research 43 986-989.

Crozier SR, Harvey NC, Inskip HM, Godfrey KM, Cooper C, Robinson SM \& Group SWSS 2012 Maternal vitamin D status in pregnancy is associated with adiposity in the offspring: findings from the Southampton Women's Survey. American Journal of Clinical Nutrition 96 57-63. (doi:10.3945/ajcn.112.037473)

Despres JP 2001 Health consequences of visceral obesity. Annals of Medicine 33 534-541. (doi:10.3109/07853890108995963)

Despres JP, Moorjani S, Lupien PJ, Tremblay A, Nadeau A \& Bouchard C 1990 Regional distribution of body fat, plasma lipoproteins, and cardiovascular disease. Arteriosclerosis 10 497-511. (doi:10.1161/01. ATV.10.4.497)

Ding C, Gao D, Wilding J, Trayhurn P \& Bing C 2012 Vitamin D signalling in adipose tissue. British Journal of Nutrition 108 1915-1923. (doi:10.1017/S0007114512003285) http://joe.endocrinology-journals.org

DOI: 10.1530/JOE-17-0015
๑) 2017 Society for Endocrinology Printed in Great Britain 
Eckhardt CL, Gernand AD, Roth DE \& Bodnar LM 2015 Maternal vitamin D status and infant anthropometry in a US multi-centre cohort study. Annals of Human Biology 42 215-222.

Erkkola M, Nwaru BI \& Viljakainen HT 2011 Maternal vitamin D during pregnancy and its relation to immune-mediated diseases in the offspring. Vitamins and Hormones 86 239-260. (doi:10.1016/b978-012-386960-9.00010-1)

Fernandes de Abreu DA, Nivet E, Baril N, Khrestchatisky M, Roman F \& Feron F 2010 Developmental vitamin D deficiency alters learning in C57Bl/6J mice. Behavioural Brain Research 208 603-608. (doi:10.1016/j.bbr.2010.01.005)

Fudge NJ \& Kovacs CS 2010 Pregnancy up-regulates intestinal calcium absorption and skeletal mineralization independently of the vitamin D receptor. Endocrinology 151 886-895. (doi:10.1210/ en.2009-1010)

Gernand AD, Simhan HN, Caritis S \& Bodnar LM 2014 Maternal vitamin $\mathrm{D}$ status and small-for-gestational-age offspring in women at high risk for preeclampsia. Obstetrics and Gynaecology 123 40-48. (doi:10.1097/ AOG.0000000000000049)

Giulietti A, Gysemans C, Stoffels K, van Etten E, Decallonne B, Overbergh L, Bouillon R \& Mathieu C 2004 Vitamin D deficiency in early life accelerates Type 1 diabetes in non-obese diabetic mice. Diabetologia 47 451-462. (doi:10.1007/s00125-004-1329-3)

Harms LR, Eyles DW, McGrath JJ, Mackay-Sim A \& Burne TH 2008 Developmental vitamin D deficiency alters adult behaviour in 129/ SvJ and C57BL/6J mice. Behavioural Brain Research 187 343-350. (doi:10.1016/j.bbr.2007.09.032)

Hashemipour S, Ziaee A, Javadi A, Movahed F, Elmizadeh K, Javadi EH \& Lalooha F 2014 Effect of treatment of vitamin D deficiency and insufficiency during pregnancy on fetal growth indices and maternal weight gain: a randomized clinical trial. European Journal of Obstetrics \& Gynecology and Reproductive Biology 172 15-19. (doi:10.1016/j. ejogrb.2013.10.010)

Kent GN, Price RI, Gutteridge DH, Rosman KJ, Smith M, Allen JR, Hickling CJ \& Blakeman SL 1991 The efficiency of intestinal calcium absorption is increased in late pregnancy but not in established lactation. Calcified Tissue International 48 293-295. (doi:10.1007/ BF02556384)

Klebig ML, Wilkinson JE, Geisler JG \& Woychik RP 1995 Ectopic expression of the agouti gene in transgenic mice causes obesity, features of type II diabetes, and yellow fur. PNAS 92 4728-4732. (doi:10.1073/pnas.92.11.4728)

Krishnaveni GV, Veena SR, Winder NR, Hill JC, Noonan K, Boucher BJ, Karat SC \& Fall CH 2011 Maternal vitamin D status during pregnancy and body composition and cardiovascular risk markers in Indian children: the Mysore Parthenon Study. American Journal of Clinical Nutrition 93 628-635. (doi:10.3945/ajcn.110.003921)

Lachance J \& Page E 1953 Hormonal factors influencing fat deposition in the interscapular brown adipose tissue of the white rat. Endocrinology 52 57-64. (doi:10.1210/endo-52-1-57)

Landsberg L 2008 Body fat distribution and cardiovascular risk: a tale of 2 sites. Archives of Internal Medicine 168 1607-1608. (doi:10.1001/ archinte.168.15.1607)

Lazar MA 2002 Becoming fat. Genes and Development 16 1-5. (doi:10.1101/gad.964002)

Lee HO, Yim JE, Lee JS, Kim YS \& Choue R 2013 The association between measurement sites of visceral adipose tissue and cardiovascular risk factors after caloric restriction in obese Korean women. Nutrition Research and Practice 7 43-48. (doi:10.4162/nrp.2013.7.1.43)

Leffelaar ER, Vrijkotte TG \& van Eijsden M 2010 Maternal early pregnancy vitamin D status in relation to fetal and neonatal growth: results of the multi-ethnic Amsterdam Born Children and their Development cohort. British Journal of Nutrition 104 108-117. (doi:10.1017/S000711451000022X)

Maia-Ceciliano TC, Barreto-Vianna AR, Barbosa-da-Silva S, Aguila MB, Faria TS \& Mandarim-de-Lacerda CA 2016 Maternal vitamin
D-restricted diet has consequences in the formation of pancreatic islet/insulin-signaling in the adult offspring of mice. Endocrine $\mathbf{5 4}$ 60-69. (doi:10.1007/s12020-016-0973-y)

Miliku K, Vinkhuyzen A, Blanken LM, McGrath JJ, Eyles DW, Burne TH, Hofman A, Tiemeier H, Steegers EA, Gaillard R, et al. 2016 Maternal vitamin $\mathrm{D}$ concentrations during pregnancy, fetal growth patterns, and risks of adverse birth outcomes. American Journal of Clinical Nutrition 103 1514-1522. (doi:10.3945/ajcn.115.123752)

Mutt SJ, Hypponen E, Saarnio J, Jarvelin MR \& Herzig KH 2014 Vitamin D and adipose tissue-more than storage. Frontiers in Physiology 5228.

Narvaez CJ, Simmons KM, Brunton J, Salinero A, Chittur SV \& Welsh JE 2013 Induction of STEAP4 correlates with 1,25-dihydroxyvitamin D3 stimulation of adipogenesis in mesenchymal progenitor cells derived from human adipose tissue. Journal of Cellular Physiology $\mathbf{2 2 8}$ 2024-2036. (doi:10.1002/jcp.24371)

Nascimento FA, Ceciliano TC, Aguila MB \& Mandarim-de-Lacerda CA 2013 Transgenerational effects on the liver and pancreas resulting from maternal vitamin D restriction in mice. Journal of Nutritional Science and Vitaminology 59 367-374. (doi:10.3177/jnsv.59.367)

Novakovic B, Galati JC, Chen A, Morley R, Craig JM \& Saffery R 2012 Maternal vitamin D predominates over genetic factors in determining neonatal circulating vitamin D concentrations. American Journal of Clinical Nutrition 96 188-195. (doi:10.3945/ ajcn.112.035683)

O’Loan J, Eyles DW, Kesby J, Ko P, McGrath JJ \& Burne TH 2007 Vitamin D deficiency during various stages of pregnancy in the rat; its impact on development and behaviour in adult offspring. Psychoneuroendocrinology 32 227-234. (doi:10.1016/j. psyneuen.2006.12.006)

Osman OS, Selway JL, Kepczynska MA, Stocker CJ, O’Dowd JF, Cawthorne MA, Arch JR, Jassim S \& Langlands K 2013 A novel automated image analysis method for accurate adipocyte quantification. Adipocyte $\mathbf{2}$ 160-164. (doi:10.4161/adip.24652)

Park S, Yoon HK, Ryu HM, Han YJ, Lee SW, Park BK, Park SY, Yim CH \& Kim SH 2014 Maternal vitamin D deficiency in early pregnancy is not associated with gestational diabetes mellitus development or pregnancy outcomes in Korean pregnant women in a prospective study. Journal of Nutritional Science and Vitaminology $60269-275$. (doi:10.3177/jnsv.60.269)

Parlee SD, Lentz SI, Mori H \& MacDougald OA 2014 Quantifying size and number of adipocytes in adipose tissue. Methods in Enzymology 537 93-122. (doi:10.1016/b978-0-12-411619-1.00006-9)

Pascot A, Lemieux S, Lemieux I, Prud'homme D, Tremblay A, Bouchard C, Nadeau A, Couillard C, Tchernof A, Bergeron J, et al. 1999 Age-related increase in visceral adipose tissue and body fat and the metabolic risk profile of premenopausal women. Diabetes Care 22 1471-1478. (doi:10.2337/diacare.22.9.1471)

Reichetzeder C, Chen H, Foller M, Slowinski T, Li J, Chen YP, Lang F \& Hocher B 2014 Maternal vitamin D deficiency and fetal programming-lessons learned from humans and mice. Kidney and Blood Pressure Research 39 315-329. (doi:10.1159/000355809)

Rosen ED \& Spiegelman BM 2000 Molecular regulation of adipogenesis. Annual Review of Cell and Developmental Biology 16 145-171. (doi:10.1146/annurev.cellbio.16.1.145)

Ross AC, Manson JE, Abrams SA, Aloia JF, Brannon PM, Clinton SK, Durazo-Arvizu RA, Gallagher JC, Gallo RL, Jones G, et al. 2011 The 2011 report on dietary reference intakes for calcium and vitamin $\mathrm{D}$ from the Institute of Medicine: what clinicians need to know. Journal of Clinical Endocrinology and Metabolism 96 53-58. (doi:10.1210/jc.2010-2704)

Sachan A, Gupta R, Das V, Agarwal A, Awasthi PK \& Bhatia V 2005 High prevalence of vitamin D deficiency among pregnant women and their newborns in Northern India. American Journal of Clinical Nutrition $\mathbf{8 1}$ 1060-1064.

Schneuer FJ, Roberts CL, Guilbert C, Simpson JM, Algert CS, Khambalia AZ, Tasevski V, Ashton AW, Morris JM \& Nassar N 2014 Effects of

Published by Bioscientifica Ltd. 
maternal serum 25-hydroxyvitamin D concentrations in the first trimester on subsequent pregnancy outcomes in an Australian population. American Journal of Clinical Nutrition 99 287-295. (doi:10.3945/ajcn.113.065672)

Spiegelman BM, Hu E, Kim JB \& Brun R 1997 PPAR gamma and the control of adipogenesis. Biochimie 79 111-112. (doi:10.1016/S03009084(97)81500-3)

Stettler N, Kumanyika SK, Katz SH, Zemel BS \& Stallings VA 2003 Rapid weight gain during infancy and obesity in young adulthood in a cohort of African Americans. American Journal of Clinical Nutrition 77 1374-1378.

Stettler N, Stallings VA, Troxel AB, Zhao J, Schinnar R, Nelson SE, Ziegler EE \& Strom BL 2005 Weight gain in the first week of life and overweight in adulthood: a cohort study of European American subjects fed infant formula. Circulation 111 1897-1903. (doi:10.1161/01.CIR.0000161797.67671.A7)

Valle YL, Almalki SG \& Agrawal DK 2016 Vitamin D machinery and metabolism in porcine adipose-derived mesenchymal stem cells. Stem Cell Research and Therapy 7 118. (doi:10.1186/s13287016-0382-4)

Villa CR, Chen J, Wen B, Sacco SM, Taibi A, Ward WE \& Comelli EM 2016 Maternal vitamin D beneficially programs metabolic, gut and bone health of mouse male offspring in an obesogenic environment. International Journal of Obesity.
Walsh JM, McGowan CA, Kilbane M, McKenna MJ \& McAuliffe FM 2012 The relationship between maternal and fetal vitamin $\mathrm{D}$, insulin resistance, and fetal growth. Reproductive Sciences 20 536-541. (doi:10.1177/1933719112459222)

Wolff GL, Kodell RL, Moore SR \& Cooney CA 1998 Maternal epigenetics and methyl supplements affect agouti gene expression in Avy/a mice. FASEB Journal 12 949-957.

Wolff GL, Roberts DW \& Mountjoy KG 1999 Physiological consequences of ectopic agouti gene expression: the yellow obese mouse syndrome. Physiological Genomics 1 151-163.

Wueest S, Yang X, Liu J, Schoenle EJ \& Konrad D 2012 Inverse regulation of basal lipolysis in perigonadal and mesenteric fat depots in mice. American Journal of Physiology: Endocrinology and Metabolism 302 E153-E160. (doi:10.1152/ajpendo.00338.2011)

Yamauchi T, Waki H, Kamon J, Murakami K, Motojima K, Komeda K, Miki H, Kubota N, Terauchi Y, Tsuchida A, et al. 2001 Inhibition of RXR and PPARgamma ameliorates diet-induced obesity and type 2 diabetes. Journal of Clinical Investigation 108 1001-1013. (doi:10.1172/JCI12864)

Zoico E, Franceschetti G, Chirumbolo S, Rossi AP, Mazzali G, Rizzatti V, Budui S \& Zamboni M 2014 Phenotypic shift of adipocytes by cholecalciferol and 1alpha,25 dihydroxycholecalciferol in relation to inflammatory status and calcium content. Endocrinology 155 4178-4188. (doi:10.1210/en.2013-1969)

Received in final form 29 June 2017

Accepted 4 July 2017

Accepted Preprint published online 4 July 2017
๑) 2017 Society for Endocrinology Printed in Great Britain
Published by Bioscientifica Ltd. 